\title{
ESTRATÉGIAS DE RESPONSABILIDADE SOCIAL DAS EMPRESAS NA INTERNET: UMA ANÁLISE COMPARATIVA DOS CONTEÚDOS DOS WEBSITES CORPORATIVOS NO BRASIL
}

\author{
Andressa Silverio Terra França \\ Doutoranda em Sociologia pela Universidade Federal do Paraná - UFPR \\ Pesquisadora da Universidade Federal do Paraná - UFPR \\ andressastf@gmail.com \\ Jose Ricardo Favoretto \\ Mestre em Administração pela Universidade Federal do Paraná - UFPR \\ Pesquisador da Universidade Federal do Paraná - UFPR \\ jose.ricardo.favoretto@gmail.com
}

\section{Sérgio Soares Braga}

Doutor em Desenvolvimento Econômico pela Universidade Estadual de Campinas - Unicamp

Professor da Universidade Federal do Paraná - UFPR

ssbraga@uol.com.br

\begin{abstract}
RESUMO
O objetivo do trabalho é apresentar uma proposta de estudo voltada para mensuração do grau de utilização da Internet pelas empresas brasileiras, visando avaliar como (e quanto) estas organizações se utilizam da web para divulgar suas ações de responsabilidade social e interagir com seus públicos de interesse. Foram selecionados para análise os websites das empresas segundo o ranking do Guia Exame de Sustentabilidade, edição de 2009. Procurou-se cumprir o objetivo da pesquisa por meio da construção de indicadores que avaliem a presença das seguintes dimensões nos websites das empresas mencionadas: 1) Navegabilidade/ Acessibilidade; (2) Informações institucionais básicas e Processos da RSC; (3) Transparência e Accountability; (4) Recursos avançados de Mídia e Comunicação; e (5) Políticas, Programas e Impactos da RSC. Os resultados da pesquisa sugerem que, a despeito do crescente engajamento das empresas brasileiras em atividades de responsabilidade social, a comunicação específica de tais elementos na internet tem se mostrado bastante deficitária, o que revela um baixo interesse destas organizações em estabelecer uma estratégia de diálogo permanente com seus públicos de interesse.
\end{abstract}

Palavras-chave: Responsabilidade Social das Empresas; Internet; Websites Corporativos; Comunicação da RSC; Diálogo com Stakeholders.

\section{STRATEGIES FOR CORPORATE SOCIAL RESPONSIBILITY IN THE INTERNET: A COMPARATIVE ANALYSIS OF THE CONTENTS OF CORPORATE WEBSITES IN BRAZIL}

\begin{abstract}
The aim of this paper is to present a proposal for measuring the use of the Internet by Brazilian companies, to evaluate how (and how much) these organizations are using the web to promote its corporate responsibility practices and interaction with the different publics. Websites of companies considered "model" in Corporate Social Responsibility in Brazil by Guia Exame ranking of Sustainability in the 2009 edition were selected for analysis. The survey results suggest that despite the increasing engagement of Brazilian companies in CSR activities, the specific communication of such information on the internet has been quite a loss, which shows a low interest of these organizations to establish a strategy to improve the relationships and dialogue between organizations and their different kinds of publics.
\end{abstract}

Key-words: Corporate Social Responsibility; Internet; Corporate 


\section{INTRODUÇÃO}

A questão da "responsabilidade social empresarial" (RSE) ou "responsabilidade social corporativa" (RSC) tem sido objeto de inúmeros trabalhos importantes desde a década de 70 (Carroll, 1979; Friedman, 1970; Davis, 1973, Frederick, 1978; Freeman, 1984; Wood, 1991; Schwartz \& Carroll, 2003, 2008; entre outros).

O assunto ganhou notoriedade, sobretudo, com a obra seminal de Howard Bowen em 1953, intitulada Social Responsibilities of the Businessman, que estruturou um conjunto de abordagens teóricas sobre a RSC e contribuiu para a discussão do tema no meio acadêmico (Carroll, 1979). Por outro lado, embora já exista uma literatura razoável sobre o assunto, constata-se que o seu conceito não se encontra ainda suficientemente consolidado e que, portanto, ainda está em processo de construção (Wood, 1991; Schwartz \& Carroll, 2003, 2008; Ashley \& Cardoso, 2002).

É interessante notar que este campo de estudos não está apenas teórica e conceitualmente inacabado como também empiricamente inexplorado. Neste sentido, alguns autores vêm chamando a atenção, por exemplo, para a questão da comunicação da RSC (Birth, Illia, Lurati \& Zamparini, 2008). O potencial para explorar esse novo campo de investigação nos levou a desenvolver uma pesquisa que buscasse examinar como os empresários no Brasil estão usando as novas tecnologias de informação e comunicação (NTICs) em geral, e a internet em particular, para divulgar suas estratégias de responsabilidade social, assim como para se comunicar com os públicos interessados.

Sendo assim, nas linhas que seguem, buscamos apresentar uma proposta de estudo voltada para mensuração do grau de utilização da Internet pelas empresas no Brasil, visando avaliar como (e quanto) estas organizações se utilizam da web para divulgar suas ações de RSC e interagir com os públicos interessados. Esse objetivo geral desdobra-se em dois objetivos específicos que são:

a) apresentar uma proposta de mensuração e avaliação dos conteúdos dos websites corporativos, visando avaliar como estas organizações se utilizam da web para divulgar suas atividades de RSE e interagir com os stakeholders;

b) elaborar e aplicar instrumentos teórico-metodológicos para a análise de tais dados, especialmente para a avaliação da eficácia da internet como instrumento de comunicação e diálogo entre as empresas e seus diferentes públicos.

Foram selecionados para análise os websites das empresas consideradas "modelo" em Responsabilidade Social Corporativa no Brasil, classificadas segundo o ranking do Guia Exame de Sustentabilidade (Editora Abril, 2009). Por meio da elaboração e aplicação de uma planilha específica, contendo informações sobre cerca de 80 variáveis, e distribuídas em 5 dimensões básicas, buscou-se examinar o conteúdo dos sites corporativos e efetuar um mapeamento abrangente das práticas de responsabilidade social adotadas por essas organizações a partir desses portais.

O trabalho está organizado da seguinte forma: a) na primeira parte estaremos recuperando os delineamentos e as implicações teóricas da literatura sobre comunicação da RSC na Internet; b) em seguida, na segunda parte, esclarecemos alguns aspectos da metodologia de análise empregada para estudar o conteúdo dos websites; c) na terceira parte discutimos os resultados obtidos através da aplicação de tal metodologia, efetuando um mapeamento descritivo e uma análise quantitativa das informações disponíveis nos portais dessas empresas; d) por fim, a partir da análise dos casos dos websites de algumas organizações empresariais mais organizadas, procuramos sintetizar aspectos mais substantivos do tema pesquisado e tecer algumas considerações finais sobre os potenciais do uso da web para uma comunicação mais transparente e eficaz das estratégias de responsabilidade social das empresas. 


\section{COMUNICAÇÃO DA RSC NA INTERNET}

O surgimento das novas tecnologias de informação e comunicação (NTICs) no final do século XX e seu posterior desenvolvimento e massificação nestes últimos anos vem suscitando importantes debates acerca de seu papel nas sociedades contemporâneas. Estudiosos, políticos, governos, e imprensa têm disseminado a idéia de que, essas novas tecnologias, principalmente a Internet, ao abrir canais de comunicação mais práticos e econômicos, diminuindo assim os custos da comunicação e interação entre os indivíduos, tem modificado a forma como as pessoas se relacionam. As organizações empresariais, como parte integrante do conjunto de instituições sociais, também não deixaria de sofrer sua influência, convertendo-se assim em objeto de estudo dos pesquisadores interessados em otimizar a eficiência de tais organizações.

A esse respeito vários autores, especialmente nos EUA, têm procurado analisar os impactos que o uso destas novas tecnologias, especialmente a internet, provoca e pode provocar na comunicação corporativa. Diversos estudos vêm mostrando a importância dessa ferramenta, bem como dos websites corporativos, nas relações com os públicos de interesse (Kent \& Taylor, 1998; White \& Raman, 1999; Hill \& White, 2000; Kent, Taylor, White, 2003), sua centralidade para comunicação das responsabilidades organizacionais (Esrock \& Leichty, 1998, 2000) ou mesmo para a organização da ação política do empresariado (Braga \& Nicolas, 2009).

Uma das características principais da Internet, e que a diferenciaria das outras mídias tradicionais (jornais, revistas, mídias externas, emissoras de televisão e rádio), é seu alto potencial interativo, que possibilita a comunicação entre os públicos de interesse e as organizações (Ha \& James, 1998; Downes \& Mcmillan, 2000). Além disso, a Internet permite que as empresas divulguem informações atualizadas e detalhadas de maneira muito mais rápida e econômica. As informações corporativas ficam disponíveis para consulta 24 horas por dia, sete dias por semana, cabendo apenas ao internauta escolher quais assuntos que deseja acessar e fazê-lo, quantas vezes considerar necessário (Silva, Wanderley, Perks \& Souza, 2007).

No que diz respeito ao grau de interatividade dos websites corporativos, Capriotti e Moreno (2007) identificam duas abordagens básicas: a divulgação de informações e a geração das relações entre os diferentes públicos e da organização. Na primeira abordagem, o nível de interatividade é baixo, e a utilização da Internet é unidirecional, com o objetivo essencial de difusão da informação e tentativa de influência sobre a imagem que as pessoas têm da organização. Na segunda abordagem, o grau de interatividade é mais elevado, e a comunicação é bidirecional. A Internet é usada para estabelecer e construir relacionamentos, permitindo o diálogo e a interação entre a organização e os diferentes tipos de públicos. Assim, outra característica peculiar da Internet é que ela permite que as empresas divulguem informações voltadas a determinados stakeholders e ainda que obtenham um feedback dos mesmos.

Esse novo campo de possibilidades propiciadas pela internet resulta também em um crescimento do uso da web para divulgar a responsabilidade social das empresas. Paralelamente ao envolvimento com ações de RSC, as empresas investem, cada vez mais, em estratégias de comunicação para que o consumidor conheça e valorize suas práticas socialmente responsáveis.

Assim, na esteira dos trabalhos acima, devemos mencionar uma bibliografia recente, e que inclusive influenciou mais de perto nosso trabalho, dedicados especificamente a analisar o papel da internet na comunicação das práticas de responsabilidade social corporativa (Esrock, Leichty, 1998; Ashley, Ferreira \& Reis, 2006; Silva et al., 2007; Capriotti \& Moreno, 2007; Santiago \& Gomes, 2008; Gill \& Dickinson, 2008).

Morsing define a comunicação da RSC como a "comunicação que é desenhada e distribuída pela própria companhia, sobre suas ações de Responsabilidade Social” (Morsing, 2006, p.171, tradução nossa). Mas, apesar das práticas comunicacionais estarem enraizadas nas corporações, a comunicação mostra-se como um dos aspectos mais controversos da RSC, porque ao mesmo tempo em que as empresas desejam que os seus stakeholders - descritos como consumidores, funcionários, 
fornecedores, acionistas, o governo e a comunidade local - estejam cientes das suas ações de responsabilidade social, elas temem as críticas e as expectativas que a comunicação das suas ações possam gerar. Apesar dessa problemática, verifica-se que tais estratégias comunicacionais utilizadas pelas companhias mostram-se, até o momento, bem pouco pesquisadas (Silva et al., 2007).

Olhando para os estudos recentes, dois canais em particular têm sido investigados e discutidos: os relatórios sociais ("Social Reporting") e os websites. No Brasil, o Balanço Social inquestionavelmente é uma demonstração sócio-contábil que conquistou grande relevância no meio empresarial principalmente nos últimos dez anos (Fiório et al., 2008). Trata-se de um demonstrativo técnico-gerencial que engloba um conjunto de informações sobre programas e/ou projetos desenvolvidos pela empresa, benefícios e ações sociais dirigidas aos empregados, investidores, analistas de mercado, acionistas, comunidade etc. Por essa razão pode ser um instrumento de análise interessante para avaliação do exercício da responsabilidade social corporativa, mas não é sobre este meio de comunicação específico de trata este artigo.

A unidade de análise tratada aqui se refere à comunicação da RSC via web. Alguns estudos mostram que as organizações vêm utilizando cada vez mais a web para comunicar suas práticas de Responsabilidade Social. Esrock e Leichty (1998) identificaram que em 1998, 50\% das empresas listadas na Revista Fortune tratava em seus websites de assuntos relacionados à responsabilidade social empresarial (incluindo temas como práticas de negócio, saúde e segurança no trabalho, segurança de produtos, diversidade cultural, meio ambiente, fillantropia, criança, educação, saúde, voluntariado, incentivos culturais, atividades cívicas e qualidade de vida no trabalho). Segundo estes autores, no ano de 2000, esse percentual teria aumentado para 80\% (Esrock \& Leichty, 2000).

Por sua vez, Pollach (2003) afirma que a internet está cada vez mais substituindo as formas tradicionais de comunicação corporativa como kits informativos, textos impressos e panfletos. Segundo a autora, os websites possuem enormes vantagens frente aos materiais impressos, em termos de custo, alcance e viabilidade, e está se transformando em meio de "autodivulgação" destinada a melhorar a reputação corporativa e antecipar a opinião pública.

Neste sentido, também podemos perceber um avanço na literatura que trata da RSC, ao propor instrumentos metodológicos diferenciados para análise dos conteúdos dos websites corporativos. Um primeiro instrumento que podemos destacar é o modelo "CSR - Web Vision", proposto originalmente por Ashley, Ferreira \& Reis (2006) para analisar e avaliar comparativamente os atributos de estratégias de responsabilidade social de quatro grandes empresas de petróleo e gás.

O interessante do modelo CSR - Web Vision é que se trata de um modelo genérico que pode ser aplicado em qualquer empresa ou organização, em diferentes segmentos de negócios. Seus componentes podem ser modificados ou suas categorias alteradas em cada uma das suas dimensões, para melhor se adaptar ao objeto em estudo. Além disso, pode, também, possibilitar uma análise comparativa de uma mesma empresa em diversos momentos ou de diferentes empresas de um mesmo segmento (Ashley et al., 2006).

Não é um instrumento de análise muito sofisticado, mas suas vantagens estão na facilidade de aplicação e em um crescente potencial de revelação de informações estratégicas de forma resumida. O principal referencial teórico adotado é o clássico artigo intitulado "Corporate Social Performance Revisited", publicado em 1991, por Donna Wood, que é um dos mais citados autores nos artigos acadêmicos sobre desempenho social corporativo. Neste artigo, Wood (1991) faz uma síntese da literatura acadêmica sobre responsabilidade social ao mesmo tempo em que constrói, com base em definições prévias de RSC, um arcabouço teórico sobre performance social corporativa (CSP). O modelo proposto pela autora define desempenho social das empresas como a configuração de princípios de responsabilidade social, processos de capacidade de resposta social e políticas, programas e resultados observáveis em relação ao comportamento da empresa, conforme mostra a Figura 1. 


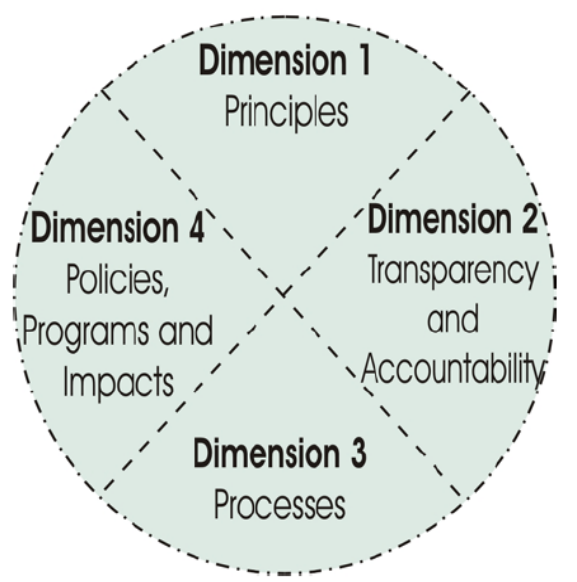

Figura 1: Fonte: ASHLEY, P. A., FERREIRA, R. N. \& REIS, H. L. (2006). Corporate Strategies for Business Comparative Model Applied in Three Continents (p.4). Anais da Rio Oil \& Gas Expo and Conference, Rio de Janeiro, RJ, Brasil.

A primeira dimensão pode ser definida como os "princípios da responsabilidade social corporativa", sendo o nível mais alto e abstrato da estratégia de RSC, que embasa o entendimento da empresa quanto ao conceito de responsabilidade social, suas crenças ou os valores básicos que as levam a agir. A segunda dimensão refere-se à "transparência e accountability", e visa avaliar o grau de transparência das atividades da empresa e sua comunicação com os públicos interessados. A terceira dimensão diz respeito aos "processos e estrutura organizacional", que é a descrição dos processos de RSC em termos de gerenciamento ambiental, governança corporativa e gerenciamento de stakeholders. Finalmente, a quarta dimensão reporta-se às "políticas, programas e impactos", que representa o comportamento observável na performance social corporativa. Trata-se da dimensão mais operacional e mensurável que é decomposta em políticas, programas e impactos sociais. É preciso esclarecer o significado de desempenho social corporativo, adotado por Wood, que é um conceito mais amplo, incluindo aspectos econômicos, ambientais e sociais, e que diz respeito a todas as relações negócios-sociedade, afetadas pela estratégia corporativa de responsabilidade social.

O referencial teórico que dá base ao modelo CSR-Web Vision é o modelo multidimensional, relacional e multidirecional para responsabilidade social nos negócios - o MRMRSN - proposto por Ashley (2005) que optam pelo conceito de empresa como rede de relacionamentos e, assim, indica que a responsabilidade social requer o compartilhamento de responsabilidades entre agentes econômicos. O modelo MRMRSN objetiva compreender e avaliar a estratégias de gestão da responsabilidade social de uma empresa.

Outra metodologia interessante foi proposta por Capriotti e Moreno (2006) para analisar a importância e a interatividade das informações sobre RSC em 35 websites de empresas espanholas. Os autores desenvolveram uma ferramenta específica para a identificação das questões de responsabilidade corporativa e para uma análise do grau de interatividade de tais informações em sites corporativos. A metodologia proposta por Capritotti e Moreno tem a vantagem de facilitar a comparação das organizações quanto à questão da responsabilidade corporativa e do grau de interatividade na relação entre organizações e seus públicos sobre esta matéria.

Cinco categorias foram estabelecidas: (1) quantidade de informação, (2) hierarquia da informação, (3) localização da informação, (4) recursos de informação, e (5) recursos de feedback. A primeira categoria permite saber se as diferentes questões estão presentes no websites e de quanta informação existe sobre as diferentes questões. A categoria "hierarquia da informação" permite identificar o nível hierárquico, ou seja, a localização das informações sobre a RSC dentro das seções da homepage. A categoria "localização da informação" possibilita a identificação dos diferentes recursos utilizados para apresentar as informações sobre a RSC. Aqui dois tipos de 
recursos foram identificados: (1) Recursos expositivos, que são aqueles que permitem a disseminação da informação tais como textos escritos e imagens, fotos e gráficos, ou audiovisual (áudio e vídeo); e (2) recursos interativos, que são aqueles que permitem que as informações sejam obtidas por meio da interatividade, como hipertextos, gráficos interativos, e outros recursos similares. A categoria "recursos de feedback" facilita a identificação dos mecanismos disponíveis nos sites corporativos para visitantes fazer perguntas, dar opiniões, ou avaliar questões relativas à RSC/ Cidadania Corporativa/ Sustentabilidade. Três tipos de feedback foram estabelecidos: (1) email geral para contato com a empresa; (2) e-mail específico para questões relacionadas à RSC; (3) outras formas de feedback (enquetes, chats, fóruns, blogs, etc.) que permitem uma avaliação ou opiniões sobre qualquer das questões relacionada à responsabilidade social. Este último tipo implica em recursos de incentivo para gerar opiniões e avaliações dos visitantes.

Finalmente, outro trabalho que influenciou diretamente a direção da metodologia empregada nesta pesquisa é o estudo realizado por Braga e Nicolas (2009) sobre o "grau de informatização" dos portais das federações das indústrias de 27 unidades subnacionais brasileiras. A análise dos sítios foi estruturada a partir do grau de recursos disponibilizados pelas associações empresariais na Web, considerando as seguintes dimensões básicas: (1) Informações gerais/navegabilidade recursos existentes nas home pages das federações e que facilitam e estimulam a navegação do internauta num primeiro contato com esses sítios; (2) Informações institucionais e sobre as elites dirigentes - funcionamento das entidades pesquisadas, organograma e composição, desde os objetivos e missão da entidade até dados sobre diretoria e atas de reunião dos conselhos. Essa dimensão abrange também informações sobre o recrutamento dos atores que participam das instâncias dirigentes e demais órgãos deliberativos das associações, bem como sobre suas rotinas administrativas; (3) Serviços básicos e oportunidades de negócios/investimentos - informações sobre serviços e oportunidades ofertados aos associados, tais como assessoria jurídica e trabalhista, e estudos sobre a conjuntura econômica, dentre outras informações sobre o comportamento dos negócios; (4) Educação e cidadania: programas voltados para atividades educacionais e de promoção da cidadania de uma maneira geral, mas sem cunho estritamente político; (5) Comunicação e informação: serviços de mídia e informação disponibilizados pela entidade, tais como: serviço de notícias, clipping, arquivos sonoros e de vídeo, e mesmo transmissão de rádio e TV on-line; (6) Economia e tecnologia: informações básicas sobre assuntos de natureza econômica e tecnológica disponibilizadas aos associados, tais como estudos e dados sobre nível de emprego, e desempenho da indústria e assim por diante; (7) Atividades políticas e cívicas - tais como: ação dos empresários industriais em órgãos legislativos, posicionamento no tocante a alguns temas básicos em debate na arena política e outras atividades de caráter cívico que demandam uma maior interação com a sociedade civil; e (8) Links para outras instituições - fato indicativo de "integração em rede" das federações de indústrias com outras associações e entidades, ou a maneira pela qual elas interagem com outros atores políticos por intermédio da web.

\section{METODOLOGIA}

A metodologia presente neste trabalho buscou incorporar elementos parciais de cada uma das técnicas de análise mencionadas acima e estruturou-se no sentido de desenvolver instrumentos que possibilitassem uma análise comparativa dos conteúdos dos websites das empresas pesquisadas, no que se refere às práticas de RSC, assim como mensurar o grau de transparência desses sítios, definido como a maior ou menor intensidade com que esses websites utilizam as NTICs e as ferramentas examinadas abaixo difundir tais práticas. Tal preocupação se corporifica na construção de alguns indicadores que possibilitem a apreensão sintética da maior ou menor amplitude da freqüência das variáveis que são objeto de exame neste artigo.

Como já registrado, procuramos cumprir esta tarefa através da elaboração e preenchimento de uma planilha específica com cerca de 80 itens ou variáveis passíveis de ser encontrados em 
websites corporativos. Sublinhe-se que o emprego dessa metodologia compatibiliza-se com algumas das motivações básicas desta pesquisa. Assim, por um lado, temos uma preocupação de ordem descritiva, na medida em que buscamos detectar a frequência de diversos aspectos ligados à RSC nos sítios das organizações examinadas, e também uma preocupação de ordem analítica, na medida em que procuraremos testar algumas hipóteses, expectativas e proposições teóricas presentes na literatura a partir do exame e discussão de tais evidências.

Sendo, procurou-se dividir os procedimentos metodológicos em dois momentos básicos:

a) Inicialmente listamos, com base na bibliografia e na consulta aos mapas de diferentes websites corporativos, uma série de elementos que consideramos relevantes para a veiculação de programas de RSC pelas empresas, bem como para a composição de nossos indicadores. A escolha das variáveis que seriam incluídas na planilha se deu com base na literatura discutida anteriormente. É importante sublinhar que, embora nosso objetivo principal fosse analisar a presença de aspectos ligados à RSC, o rendimento analítico desse objetivo de ordem geral complementou-se com a necessidade de mapear outras dimensões, a priori, também relevantes para o desempenho social das empresas e que dizem respeito a aspectos mais gerais do funcionamento destas organizações.

b) No que se refere à segunda etapa de nossa metodologia de análise, outra questão enfrentada foi quanto aos critérios para pontuação dos sites, já que os conteúdos podem ser disponibilizados de maneira bastante desigual pelas empresas. Procuramos resolver tal problema pontuando as variáveis analisadas de acordo com a seguinte escala ordinal:

Tabela 1: Critérios de pontuação

\begin{tabular}{|c|c|c|c|}
\hline $\begin{array}{c}\text { Avaliação } \\
\mathbf{1}\end{array}$ & $\begin{array}{c}\text { Informações } \\
\text { completas } \\
\text { e/ou satisfatórias } \\
\text { 2 Tipo de Informação }\end{array}$ & $\begin{array}{c}\text { Informações } \\
\text { incompletas } \\
\text { e/ou insatisfatórias } \\
(\mathbf{i})\end{array}$ & $\begin{array}{c}\text { Sem } \\
\text { informação } \\
(\mathbf{0})\end{array}$ \\
\hline Importante e essencial & 10 & 5 & 0 \\
\hline Importante, mas não essencial & 10 & 5 & 0 \\
\hline Menos importante & 10 & 5 & 0 \\
\hline
\end{tabular}

Cabe sublinhar que não elaboramos nenhum indicador mais detalhado ponderando as variáveis segundo sua importância relativa para o conceito de Responsabilidade Social Empresarial, como já feito em estudo anterior (Braga \& Nicolas, 2009). Para fins deste trabalho, foi adotado apenas um critério de pontuação, considerando a presença (ou não) dos conteúdos nos websites sem a aplicação de nenhum fator de ponderação das variáveis para a composição dos índices apresentados a seguir.

A análise dos conteúdos na internet foi estruturada a partir do grau de recursos disponibilizados pelas organizações empresariais em seus websites, considerando as seguintes dimensões básicas:

- DIMENSÃO 1: Navegabilidade/ Acessibilidade - recursos existentes nas home pages das companhias e que facilitam e estimulam a navegação do internauta num primeiro contato com esses sítios.

- DIMENSÃO 2: Informações institucionais básicas e Processos da RSC - informações sobre o funcionamento das empresas pesquisadas, desde o histórico, missão e visão, biografia dos dirigentes, assim como de detalhes mais aprofundados sobre os processos e estrutura organizacional para tratar da responsabilidade social.

- DIMENSÃO 3: Transparência e Accountabilty - são informações que dizem respeito à prestação de contas da empresa e sua comunicação com o público interessado, tais como Relatórios Anuais, demonstrações financeiras, comunicados aos acionistas, até informações sobre oportunidades de carreira oferecidas pela empresa.

- DIMENSÃO 4: Recursos avançados de mídia e comunicação - referem-se aos canais de diálogo permanente com os stakeholders, podendo ser desde e-mails para contato, website 
específico, até disponibilização de enquetes, fóruns de discussão sobre temas ligados à RSC/ Sustentabilidade.

- DIMENSÃO 5: Políticas, Programas e Impactos da RSC - são informações a respeito das estratégias de responsabilidade social propriamente ditas, desde projetos/ programas desenvolvidos, parcerias realizadas, apoios e patrocínios, até resultados observados.

São estas, em nosso entendimento, as dimensões mais relevantes ligadas à responsabilidade social e que devem constar nos websites das empresas. Grosso modo, elas traduzem detalhamentos e correspondem às funções básicas (acessibilidade ao público interessado, informações sobre a empresa, organização da ação social, comunicação e participação, diálogo e interação, conexão em rede com outros atores etc.) que podem ser desempenhadas pelas NTICs para facilitar a comunicação entre empresas e indivíduos e divulgação de informações relacionadas à RSC.

As empresas analisadas estão enumeradas no Quadro 1, acompanhadas do setor a que pertencem, origem do controle acionário, e respectivo endereço eletrônico. Ao todo foram analisados vinte websites corporativos. A escolha das empresas seguiu a classificação apresentada no Guia Exame de Sustentabilidade (Editora Abril, 2009), a partir do qual efetuou-se uma busca pela internet a fim de detectar os respectivos endereços eletrônicos.

Quadro 1: Relação de Empresas Pesquisadas

\begin{tabular}{|c|c|c|c|l|}
\hline N & EMPRESA & SETOR & CONTROLE & WEBSITE \\
\hline 1 & Wal-Mart & varejo & americano & www.walmart.com.br \\
\hline 2 & AES Brasil & energia & amer./bras. & www.aesbrasil.com.br \\
\hline 3 & Alcoa & siderurgia e metalurgia & americano & www.alcoa.com.br \\
\hline 4 & Amanco & indústria da construção & mexicano & www.amanco.com.br \\
\hline 5 & Anglo American & mineração & inglês & www.angloamerican.com.br \\
\hline 6 & Bradesco & financeiro & brasileiro & www.bradesco.com.br \\
\hline 7 & Brasil Foods & indústria de alimentos & brasileiro & www.perdigao.com.br \\
\hline 8 & Bunge Alimentos & bens de consumo & holandês & www.bunge.com.br \\
\hline 9 & Coelce & energia & espanhol & www.coelce.com.br \\
\hline 10 & CPFL & energia & brasileiro & www.cpfl.com.br \\
\hline 11 & EDP & energia & português & www.energiasdobrasil.com.br \\
\hline 12 & Fibria & papel e celulose & brasileiro & www.fibria.com.br \\
\hline 13 & Itaú Unibanco & financeiro & brasileiro & www.itau.com.br \\
\hline 14 & Masisa & indústria da construção & brasileiro & $\underline{\text { www.natura.com.br }}$ \\
\hline 15 & Natura & bens de consumo & holandês & www.philips.com.br \\
\hline 16 & Philips & eletroeletrônico & brasileiro & $\underline{\text { www.promon.com.br }}$ \\
\hline 17 & Promon & serviços & irlandês & www.serasa.com.br \\
\hline 18 & Serasa Experian & serviços & brasileiro & www.suzano.com.br \\
\hline 19 & Suzano & papel e celulose & $\underline{\text { www.tetrapak.com.br }}$ \\
\hline 20 & Tetra Pak & processamento e envase de alimentos & sueco & \\
\hline
\end{tabular}

Fonte: Editora Abril (2009)

É importante ainda sublinhar que não foram analisados os conteúdos dos documentos escritos e anexos disponíveis para downloads nos portais das empresas (como por exemplo os relatórios sociais). Isto porque o objetivo foi identificar as informações, o seu nível de presença e relevância dada a cada questão nas páginas web, supondo que esta investigação é realizada no intuito de verificar, descrever, comparar e analisar como a divulgação destas atividades está sendo feita pelas empresas em seus websites. 


\section{ANÁLISE E DISCUSSÃO DOS RESULTADOS}

Passamos agora à análise dos resultados de nossa pesquisa sobre websites corporativos no Brasil, cujos dados foram coletados a partir de visita aos sites daquelas organizações entre os meses janeiro e fevereiro de 2010. As informações contidas neste artigo, portanto, foram atualizadas até esta última data, embora incluam certa margem de erro devido ao grande número de "experimentos" necessários para a comprovação da funcionalidade das variáveis observadas, bem como à natureza "dinâmica" da organização das home pages.

No tocante aos itens que foram pesquisados, coletamos dados sobre cerca de 80 variáveis dispostas nos websites das empresas pesquisadas. Destes itens, 55 deles se referem predominantemente às funções de informação-transparência ("inf") e outros 25 às funções de comunicação-interação ("com"), revelando que a disponibilização de ferramentas de interatividade pelas empresas já está razoavelmente presente nos websites de boa parte delas, embora sua funcionalidade, como será visto adiante, ainda esteja longe do ideal.

\subsection{Análise dos Conteúdos dos Websites}

\subsubsection{Navegabilidade/ Acessibilidade}

A primeira dimensão da análise refere-se às variáveis de "navegabilidade e acessibilidade" disponíveis ao público na "porta de entrada" dos websites, e que permitem o primeiro contato do internauta com a empresa na internet, como mecanismos de busca e ajuda, mapa do site, acessibilidade para deficientes físicos, e-mail de contato com a empresa, etc. Neste tópico, avaliamos a ocorrência de alguns itens devido à sua importância para a orientação inicial do cidadão que navega pela internet, bem como para tornar a navegação nas home pages mais estimulante, sem informações de difícil apreensão. Desta maneira, um maior grau de presença de tais itens nos portais, a priori, revelaria a preocupação de seus gestores em atingir todos os públicos de interesse. Os resultados são apresentados na Tabela 2.

Tabela 2: Navegabilidade/ Acessibilidade

\begin{tabular}{|c|c|c|c|c|c|c|c|}
\hline \multicolumn{2}{|r|}{ Variáveis } & \multicolumn{2}{|c|}{$\begin{array}{l}\text { Informações } \\
\text { satisfatórias }\end{array}$} & \multicolumn{2}{|c|}{ Insatisfatórias } & \multicolumn{2}{|c|}{ Sem informação } \\
\hline & & $\mathrm{N}$ & $\%$ & $\mathrm{~N}$ & $\%$ & $\mathrm{~N}$ & $\%$ \\
\hline 1 & Mecanismos de busca no site & 18 & 90,0 & - & - & 2 & 10,0 \\
\hline 2 & Fácil acesso a e-mail/ Fale conosco & 17 & 85,0 & 1 & 5,0 & 2 & 10,0 \\
\hline 3 & Link para "mapa do site" & 15 & 75,0 & 1 & 5,0 & 4 & 20,0 \\
\hline 4 & Página em outro idioma & 13 & 65,0 & 1 & 5,0 & 6 & 30,0 \\
\hline 5 & Link de volta para a página inicial visível & 13 & 65,0 & 6 & 30,0 & 1 & 5,0 \\
\hline 6 & Feeds de atualização de conteúdos/ "RSS" & 7 & 35,0 & - & - & 13 & 65,0 \\
\hline 7 & Mecanismos de Ajuda/ FAQ & 6 & 30,0 & - & - & 14 & 70,0 \\
\hline 8 & Link para avaliação do site & 4 & 20,0 & 1 & 5,0 & 15 & 75,0 \\
\hline 9 & Sugestões de melhoria & 4 & 20,0 & - & - & 16 & 80,0 \\
\hline 10 & Acessibilidade para deficientes & 3 & 15,0 & 1 & 5,0 & 16 & 80,0 \\
\hline 11 & Estatística de navegação/ número de visitas & - & - & - & - & 20 & 100,0 \\
\hline
\end{tabular}

Fonte: dados da pesquisa

Com efeito, pela tabela podemos observar uma acentuada heterogeneidade dos websites no que se refere à disponibilização de itens que facilitem a navegabilidade do cidadão-internauta, propiciando recursos básicos para uma navegação mais ativa além da mera recepção passiva de mensagens. O mecanismo de busca foi o item mais disponibilizado (90\%), seguido pela disponibilização de formulários-padrão para contato por e-mail/ fale conosco (85\%) e link para mapa do site $(75 \%)$. 
Por outro lado, itens que possibilitariam maior interatividade do público interessado com os portais, tais como "sugestões de melhoria" e "link para avaliação do portal" (20\%), ou acessibilidade para deficientes físicos $(15 \%)$ ainda são fracamente presentes, evidenciando um subaproveitamento dos portais no sentido de promover uma maior interação com os stakeholders.

\subsubsection{Informações institucionais básicas e Processos da RSC}

A segunda dimensão analisada abrange itens disponibilizados nos websites que propiciam um conhecimento mais detalhado sobre o funcionamento das empresas, ou seja, são informações básicas que permitem ao público interessado construir uma opinião sobre estas organizações, assim como ter um maior acesso a informações básicas relacionadas às prestação de contas das organizações à comunidade mais ampla dentro da qual elas se inserem no que se refere a divulgação de algumas de suas rotinas administrativas e organograma

Um dos itens mais importantes desta dimensão é a disponibilização de dados detalhados sobre a administração, a missão e visão da empresa, seu código de conduta/ código de ética, a biografia e trajetória dos dirigentes, assim como de detalhes mais aprofundados sobre os processos e estrutura organizacional para tratar da responsabilidade social, por exemplo, a existência de um comitê executivo de RSC, de uma área específica (Instituto, Fundação ou Associação), além da disponibilização de canais de contato com essas áreas.

As variáveis constantes nos websites sob a dimensão "informação" das empresas analisadas estão resumidas na Tabela 3.

Tabela 3: Informações institucionais básicas e Processos da RSC

\begin{tabular}{|c|c|c|c|c|c|c|c|c|}
\hline \multirow{2}{*}{\multicolumn{3}{|c|}{ Variáveis }} & \multirow{2}{*}{\multicolumn{2}{|c|}{$\begin{array}{l}\text { Informações } \\
\text { satisfatórias }\end{array}$}} & \multicolumn{2}{|c|}{ Insatisfatórias } & \multicolumn{2}{|c|}{$\begin{array}{c}\text { Sem } \\
\text { informação }\end{array}$} \\
\hline & & & & & & & & \\
\hline 1 & Missão, Visão e Valores & inf & $\frac{\mathrm{N}}{18}$ & $\begin{array}{c}\% \\
90,0\end{array}$ & $\begin{array}{c}\mathrm{N} \\
1\end{array}$ & $\frac{\%}{5,0}$ & $\frac{N}{1}$ & $\begin{array}{c}\% \\
5,0\end{array}$ \\
\hline 2 & $\begin{array}{l}\text { Link para "Responsabilidade Social" na página } \\
\text { inicial }\end{array}$ & $\inf$ & 15 & 75,0 & 1 & 5,0 & 4 & 20,0 \\
\hline 3 & Histórico, Perfil da empresa & inf & 14 & 70,0 & 5 & 25,0 & 1 & 5,0 \\
\hline 4 & Linha de produtos e serviços oferecidos & inf & 14 & 70,0 & 3 & 15,0 & 3 & 15,0 \\
\hline 5 & Código de conduta, Código de ética & inf & 12 & 60,0 & - & - & 8 & 40,0 \\
\hline 6 & Estrutura acionária & inf & 11 & 55,0 & - & - & 9 & 45,0 \\
\hline 7 & Informações sobre a Administração & inf & 11 & 55,0 & 4 & 20,0 & 5 & 25,0 \\
\hline 8 & Composição da diretoria/ conselhos & inf & 11 & 55,0 & 3 & 15,0 & 6 & 30,0 \\
\hline 9 & Unidades onde mantém operações & inf & 10 & 50,0 & 3 & 15,0 & 7 & 35,0 \\
\hline 10 & Área específica de RSC (Instituto, Fundação) & inf & 10 & 50,0 & 3 & 15,0 & 7 & 35,0 \\
\hline 11 & Relacionamento com as partes interessadas & inf & 8 & 40,0 & 2 & 10,0 & 10 & 50,0 \\
\hline 12 & Comitês temáticos & inf & 8 & 40,0 & - & - & 12 & 60,0 \\
\hline 13 & Informações biográficas/CV dos executivos & inf & 8 & 40,0 & 1 & 5,0 & 11 & 55,0 \\
\hline 14 & Organograma completo da Empresa & inf & 5 & 25,0 & 2 & 10,0 & 13 & 65,0 \\
\hline 15 & Comitê interno de Responsabilidade Social & inf & 2 & 10,0 & 5 & 25,0 & 13 & 65,0 \\
\hline 16 & E-mail de contato com área de RSC & com & 2 & 10,0 & 2 & 10,0 & 16 & 80,0 \\
\hline 17 & E-mail para contato com diretores & com & - & - & - & - & 20 & 100,0 \\
\hline
\end{tabular}


Pela tabela constamos que, à diferença da anterior, a utilização destes itens é mais homogênea, e apresenta maiores porcentagens, evidenciando que as empresas estão investindo mais em itens que possibilitam uma maior informação aos cidadãos, mas ainda num nível "top down" de comunicação, sem disponibilização de mecanismos de accountability que permitam uma maior interação ou comunicação com os cidadãos. No momento em que realizamos a coleta de dados, a maioria dos websites fornecia informações satisfatórias sobre missão, visão e valores da empresa (90\%), uma porcentagem menor de websites possuía informações claras sobre o histórico/ perfil da empresa e linha de produtos/ serviços oferecidos (70\%), além do código de conduta/ código de ética (60\%), o que revela o uso já institucionalizado destes itens. Por outro lado, informações relativas à administração da empresa em geral, a estrutura organizacional, e sobre o perfil dos dirigentes/ executivos foram pouco disponibilizados.

Finalmente, no que se refere às informações relacionadas à divulgação das áreas de RSC, o desempenho dos websites corporativos foi pouco satisfatório. Apesar da maioria dos websites apresentarem link para "responsabilidade social" na página inicial (75\%), poucas empresas disponibilizavam informações satisfatórias sobre as áreas formais dedicadas à responsabilidade social ou sustentabilidade das empresas (Comitê interno, Instituto, Fundação ou Associação). Além disso, apenas $10 \%$ das empresas apresentaram apresentou e-mail de contato com o pessoal responsável pela área, o que evidencia o baixo interesse por parte das companhias em divulgar, incentivar ou motivar o contato do público com a área de RSC de tais organizações.

\subsubsection{Transparência e Accountability}

Uma importante dimensão do desempenho social das empresas é a disponibilização de dados sobre prestação de contas da empresa, assim como de detalhes mais aprofundados sobre o processo decisório e deliberativo de tais organizações, por exemplo as atas de reuniões e editais de convocação para assembléias e conselhos, entre outras informações que contribuem para aproximar as empresas de outros atores sociais, tornando suas ações e deliberações mais transparentes perante os públicos de interesse. Com efeito, a presença de tais itens nos portais corporativos revela um elevado grau de comprometimento das empresas com a transparência e a prestação de contas aos cidadãos sobre a estrutura de seu processo decisório, relevando a intenção de estabelecer uma comunicação mais ativa com os stakeholders e não apenas com o público interno à organização.

É evidente que, quanto mais informações sobre a prestação de contas da empresa e quanto mais sistematicamente elas forem apresentadas, maior a possibilidade para os cidadãos e potenciais parceiros das empresas de acompanhar a trajetória destas organizações, agregando assim accountability às mesmas. Assim, a disponibilização de relatórios sociais e financeiros da empresa, bem como a publicização de aspectos relevantes de seus centros decisórios na internet demonstra uma preocupação das empresas em estabelecer uma gestão transparente e acessível para o público em geral e não apenas a seus acionistas/ investidores.

Tabela 4: Transparência e Accountability

\begin{tabular}{|c|c|c|c|c|c|c|c|c|}
\hline \multirow{2}{*}{\multicolumn{3}{|c|}{ Variáveis }} & \multicolumn{2}{|c|}{$\begin{array}{l}\text { Informações } \\
\text { satisfatórias }\end{array}$} & \multicolumn{2}{|c|}{ Insatisfatórias } & \multicolumn{2}{|c|}{$\begin{array}{c}\text { Sem } \\
\text { informação }\end{array}$} \\
\hline & & & $\mathrm{N}$ & $\%$ & $\mathrm{~N}$ & $\%$ & $\mathrm{~N}$ & $\%$ \\
\hline 1 & $\begin{array}{l}\text { Relatórios sociais nos modelos Ibase, Global } \\
\text { Reporting Initiative (GRI) ou próprio }\end{array}$ & inf & 19 & 95,0 & 1 & 5,0 & - & - \\
\hline 2 & Relatórios Sociais em mais de um idioma & inf & 16 & 80,0 & 1 & 5,0 & 3 & 15,0 \\
\hline 3 & Relatórios de Prestação de contas Anuais/ Trim. & $\inf$ & 10 & 50,0 & 2 & 10,0 & 8 & 40,0 \\
\hline 4 & Informativos e comunicados aos acionistas & $\inf$ & 10 & 50,0 & - & - & 10 & 50,0 \\
\hline 5 & Calendário de eventos corporativo & inf & 10 & 50,0 & 1 & 5,0 & 9 & 45,0 \\
\hline 6 & Estatuto Social da Empresa & $\inf$ & 10 & 50,0 & - & - & 10 & 50,0 \\
\hline
\end{tabular}

Revista de Gestão Social e Ambiental - RGSA, São Paulo, v. 5, n. 3, p. 150-167, set./dez. 2011. 
Estratégias de responsabilidade social das empresas na internet: uma análise comparativa dos conteúdos dos Websites corporativos no Brasil

\begin{tabular}{|c|l|c|c|c|c|c|c|c|}
\hline 7 & Oportunidades de emprego e estágio & inf & 10 & 50,0 & 5 & 25,0 & 5 & 25,0 \\
\hline 8 & Informações sobre cotações das ações & inf & 9 & 45,0 & - & - & 11 & 55,0 \\
\hline 9 & Relatórios CVM & inf & 8 & 40,0 & - & - & 12 & 60,0 \\
\hline 10 & Atas de reuniões dos conselhos & inf & 8 & 40,0 & - & - & 12 & 60,0 \\
\hline 11 & $\begin{array}{l}\text { Link para "Governança Corporativa" na página } \\
\text { inicial }\end{array}$ & inf & 6 & 30,0 & - & - & 14 & 70,0 \\
\hline 12 & Comitê de Governança Corporativa & inf & 6 & 30,0 & - & & 14 & 70,0 \\
\hline 13 & Política de Governança Corporativa & inf & 3 & 15,0 & - & - & 17 & 85,0 \\
\hline 14 & Editais de convocação para as assembléias & inf & 3 & 15,0 & - & - & 17 & 85,0 \\
\hline 15 & Relatórios da Administração & inf & 2 & 10,0 & - & - & 18 & 90,0 \\
\hline 16 & Regulamentos e Políticas em pdf & inf & 2 & 10,0 & 4 & 20,0 & 14 & 70,0 \\
\hline 17 & Planejamento Estratégico com foco em RSC & inf & 1 & 5,0 & - & - & 19 & 95,0 \\
\hline
\end{tabular}

Fonte: Dados da pesquisa.

Assim como no tocante à dimensão anteriormente examinada, os dados apresentados na Tabela 4 revelam que há uma acentuada desigualdade no grau de disponibilidade de informação sobre os seus centros decisórios entre as empresas analisadas. Neste sentido, ao mesmo tempo em que todas as companhias examinadas disponibilizavam os relatórios anuais de responsabilidade social em seus websites, o mesmo não pode ser dito em relação aos relatórios financeiros anuais ou trimestrais, onde a porcentagem é menor (50\%).

Informações sobre o planejamento estratégico da empresa com foco em responsabilidade social também são quase inexistentes: apenas uma empresa disponibilizava esta informação em seu website, o que em última instância compromete uma visão mais crítica a respeito do conceito e dimensões da gestão socialmente responsável. As demais informações destinadas aos acionistas/ investidores estavam razoavelmente dispostas nos websites das empresas pesquisadas (informativos e comunicados, atas de reuniões dos conselhos, calendário de eventos corporativo, etc.).

\subsubsection{Recursos avançados de mídia e comunicação}

No tocante a esta dimensão, coletamos informações sobre 17 itens, todos eles desempenhando predominantemente a função de comunicação e interação, cujas frequiências estão resumidas na Tabela 5. Além da menor freqüência, pode-se observar que o percentual de presença dos itens que possibilitam uma maior interatividade do público de interesse com as organizações empresariais também é significativamente inferior, indicando que parece ser correta a percepção de que os websites corporativos das empresas possuem um baixíssimo nível de interatividade em se tratando de temas relacionados à responsabilidade social corporativa/ sustentabilidade/ cidadania empresarial (Capriotti \& Moreno, 2007).

Neste sentido pode-se afirmar que os websites assumem uma função eminentemente de natureza informativa/ unidirecional, e menos como um canal de efetiva participação e interação entre a empresa e seus públicos de interesse. $\mathrm{O}$ uso de recursos interativos ainda é marginal na maior parte das organizações estudadas: ainda são informações "top down", verticalizadas e unidirecionais as que predominam na maior parte dos websites corporativos brasileiros. 
Tabela 5: Recursos avançados de mídia e comunicação

\begin{tabular}{|c|c|c|c|c|c|c|c|c|}
\hline \multirow{2}{*}{\multicolumn{3}{|c|}{ Variáveis }} & \multicolumn{2}{|c|}{$\begin{array}{l}\text { Informações } \\
\text { satisfatórias }\end{array}$} & \multicolumn{2}{|c|}{ Insatisfatórias } & \multicolumn{2}{|c|}{$\begin{array}{c}\text { Sem } \\
\text { informação }\end{array}$} \\
\hline & & & $\mathrm{N}$ & $\%$ & $\mathrm{~N}$ & $\%$ & $\mathrm{~N}$ & $\%$ \\
\hline 1 & Cadastro de CV on-line/ Banco de currículos & com & 17 & 85,0 & 1 & 5,0 & 2 & 10,0 \\
\hline 2 & Agenda de notícias própria & com & 14 & 70,0 & 1 & 5,0 & 5 & 25,0 \\
\hline 3 & Formulário para recebimento de newsletter & com & 11 & 55,0 & - & - & 9 & 45,0 \\
\hline 4 & Livros e outras publicações em pdf & com & 10 & 50,0 & - & - & 10 & 50,0 \\
\hline 5 & Canal de relacionamento com Investidores/ RI & com & 10 & 50,0 & 2 & 10,0 & 8 & 40,0 \\
\hline 6 & Canal de relacionamento com Fornecedores/ Portal & com & 9 & 45,0 & - & - & 11 & 55,0 \\
\hline 7 & Canal de relacionamento com Clientes/ SAC & com & 9 & 45,0 & 1 & 5,0 & 10 & 50,0 \\
\hline 8 & Jornal/ Revista da organização para download & com & 8 & 40,0 & 1 & 5,0 & 11 & 55,0 \\
\hline 9 & Link para Twitter & com & 8 & 40,0 & - & - & 12 & 60,0 \\
\hline 10 & Flicks/acervo de fotos/ imagens para downloads & com & 6 & 30,0 & - & - & 14 & 70,0 \\
\hline 11 & $\begin{array}{l}\text { Enquete sobre temas ligados à } \\
\text { RSC/Sustentabilidade }\end{array}$ & com & 5 & 25,0 & - & - & 15 & 75,0 \\
\hline 12 & Acervo de vídeos/ youtube & com & 4 & 20,0 & - & - & 16 & 80,0 \\
\hline 13 & Canal específico para denúncias & com & 4 & 20,0 & 1 & 5,0 & 15 & 75,0 \\
\hline 14 & Link para Blog & com & 3 & 15,0 & - & - & 17 & 85,0 \\
\hline 15 & Acervo de áudio/podcasts & com & 2 & 10,0 & 1 & 5,0 & 17 & 85,0 \\
\hline 16 & Notícias atualizadas da imprensa & com & 1 & 5,0 & - & - & 19 & 95,0 \\
\hline 17 & Chat/ fórum/ discussão sobre temas ligados à RSC & com & 1 & 5,0 & 1 & 5,0 & 18 & 90,0 \\
\hline
\end{tabular}

Fonte: Dados da pesquisa.

Pode-se observar pela Tabela que apenas $40 \%$ dos websites das empresas no Brasil apresentaram links específicos para o Twitter, ou Blog (15\%), e proporção bastante inferior disponibilizou enquetes sobre temas específicos ligados à RSC/ Sustentabilidade, Chat/ fóruns de discussão sobre o tema ou congêneres.

\subsubsection{Políticas, Programas e Impactos da RSC}

Esta dimensão constitui-se a parte mais importante deste trabalho. Neste item avaliamos a presença de informações básicas sobre a atuação social das empresas tais como a divulgação de informações especificando quais são os projetos e/ ou programas sociais internos e externos, os resultados e impactos das ações sociais, a identificação dos possíveis parceiros relacionados à RSC, dentre outras informações consideradas importantes.

Em relação aos indicadores propostos nesta dimensão, nota-se que o principal item disponibilizado pelas companhias em seus websites se refere à divulgação de informações sobre os programas e/ ou projetos ambientais. Tal fato se explica pela própria relevância da discussão ambiental no plano mundial atual e a necessidade latente das empresas em construir uma imagem ambientalmente responsável. Aqui é importante lembrar que existe uma notável heterogeneidade no que as empresas entendem por "responsabilidade social". Em outras palavras, nem sempre as companhias se utilizam do mesmo conceito para dar significado às ações ou percepções acerca do papel social das empresas: enquanto algumas falam explicitamente de "responsabilidade social", outras preferem o termo "sustentabilidade", por exemplo - e, no entanto, ambas podem estar se referindo ao mesmo conjunto de idéias, segundo o qual a empresa é percebida como tendo um papel 
social, no desenvolvimento do país e até mesmo na resolução das questões sociais. Deve-se notar ainda que apenas $25 \%$ das empresas divulgou em seu website uma definição clara para RSC ou sua visão sobre o conceito, evidenciando existir amplo espaço para uma melhor divulgação e propagação deste conceito entre as firmas.

Tabela 5: Políticas, Programas e Impactos da RSC

\begin{tabular}{|c|c|c|c|c|c|c|c|c|}
\hline \multirow{2}{*}{\multicolumn{3}{|c|}{ Variáveis }} & \multicolumn{2}{|c|}{$\begin{array}{l}\text { Informações } \\
\text { satisfatórias }\end{array}$} & \multicolumn{2}{|c|}{ Insatisfatórias } & \multicolumn{2}{|c|}{$\begin{array}{c}\text { Sem } \\
\text { informação }\end{array}$} \\
\hline & & & $N$ & $\%$ & $N$ & $\%$ & $\mathrm{~N}$ & $\%$ \\
\hline 1 & Programas e/ou projetos ambientais & inf & 15 & 75,0 & 2 & 10,0 & 3 & 15,0 \\
\hline 2 & Programas e/ou projetos sociais externos & inf & 14 & 70,0 & 3 & 15,0 & 3 & 15,0 \\
\hline 3 & Prêmios e reconhecimentos & inf & 12 & 60,0 & - & - & 8 & 40,0 \\
\hline 4 & Pactos, compromissos voluntários assinados & inf & 11 & 55,0 & 1 & 5,0 & 8 & 40,0 \\
\hline 5 & Parcerias com organizações relacionadas à RSC & inf & 10 & 50,0 & 1 & 5,0 & 9 & 45,0 \\
\hline 6 & Certificações & inf & 9 & 45,0 & - & - & 11 & 55,0 \\
\hline 7 & Programas e/ou projetos sociais internos & inf & 8 & 40,0 & 2 & 10,0 & 10 & 50,0 \\
\hline 8 & Patrocínios e/ou projetos apoiados & $\inf$ & 7 & 35,0 & - & - & 13 & 65,0 \\
\hline 9 & Filantropia, doações, voluntariado & $\inf$ & 7 & 35,0 & 3 & 15,0 & 10 & 50,0 \\
\hline 10 & Parcerias com universidades/ escolas & inf & 7 & 35,0 & - & - & 13 & 65,0 \\
\hline 11 & Definição de RSC/ visão sobre Sustentabilidade & inf & 5 & 25,0 & - & - & 15 & 75,0 \\
\hline 12 & $\begin{array}{l}\text { Contribuições para agenda local, regional, } \\
\text { nacional ou global }\end{array}$ & $\inf$ & 5 & 25,0 & 1 & 5,0 & 14 & 70,0 \\
\hline 13 & Política de RSC/ Sustentabilidade & $\inf$ & 4 & 20,0 & 2 & 10,0 & 14 & 70,0 \\
\hline 14 & Participação em projetos governamentais & $\inf$ & 2 & 10,0 & 1 & 5,0 & 17 & 85,0 \\
\hline 15 & Práticas anti-corrupção e anti-propina & $\inf$ & 2 & 10,0 & 2 & 10,0 & 16 & 80,0 \\
\hline 16 & Contribuições para campanhas políticas/ cívicas & inf & 1 & 5,0 & 1 & 5,0 & 18 & 90,0 \\
\hline 17 & Financiamento da ação social & inf & 1 & 5,0 & - & - & 19 & 95,0 \\
\hline 18 & Resultados, impactos dos projetos & inf & - & - & - & - & 20 & 100,0 \\
\hline
\end{tabular}

Fonte: Dados da pesquisa.

Já no que se refere à divulgação de informações sobre projetos sociais internos e/ ou externos executados pela empresa, a maioria dos websites apresentou resultado satisfatório, embora não existam informações precisas sobre o valor dos investimentos realizados nem sobre os resultados efetivos dos projetos implementados. É certo que a maioria delas o faz em seu relatório de sustentabilidade que está disponível para download, no entanto, tal fato deixa de atender na íntegra este quesito, já que a comunicação dos resultados poderia ser de mais fácil acesso ao internauta sendo disponibilizado diretamente no website. Assim, o que se pode perceber, é que falta às empresas investir na divulgação de informações mais aprofundadas e de maior qualidade sobre esses projetos (especificando, por exemplo, a quantidade de pessoas e organizações atendidas, benefícios para o público-alvo, recursos humanos, financeiros e materiais investidos, dentre outras informações), já que os investidores, os stakeholders e a sociedade em geral se interessam por tais informações.

Outros resultados da pesquisa poderiam aqui ser comentados, no entanto, por razões de 
espaço, encerramos aqui a análise dos conteúdos e passamos agora para uma breve descrição do desempenho geral dos websites.

\subsection{Pontuação geral dos Websites}

$\mathrm{Na}$ análise da pontuação geral dos websites, o que se pode perceber é que a maioria das páginas das companhias não atingiu uma pontuação satisfatória, com uma utilização média de apenas $42 \%$ dos recursos de comunicação e informação disponíveis na web. As porcentagens obtidas por cada uma das empresas encontram-se resumidas no Gráfico 1.

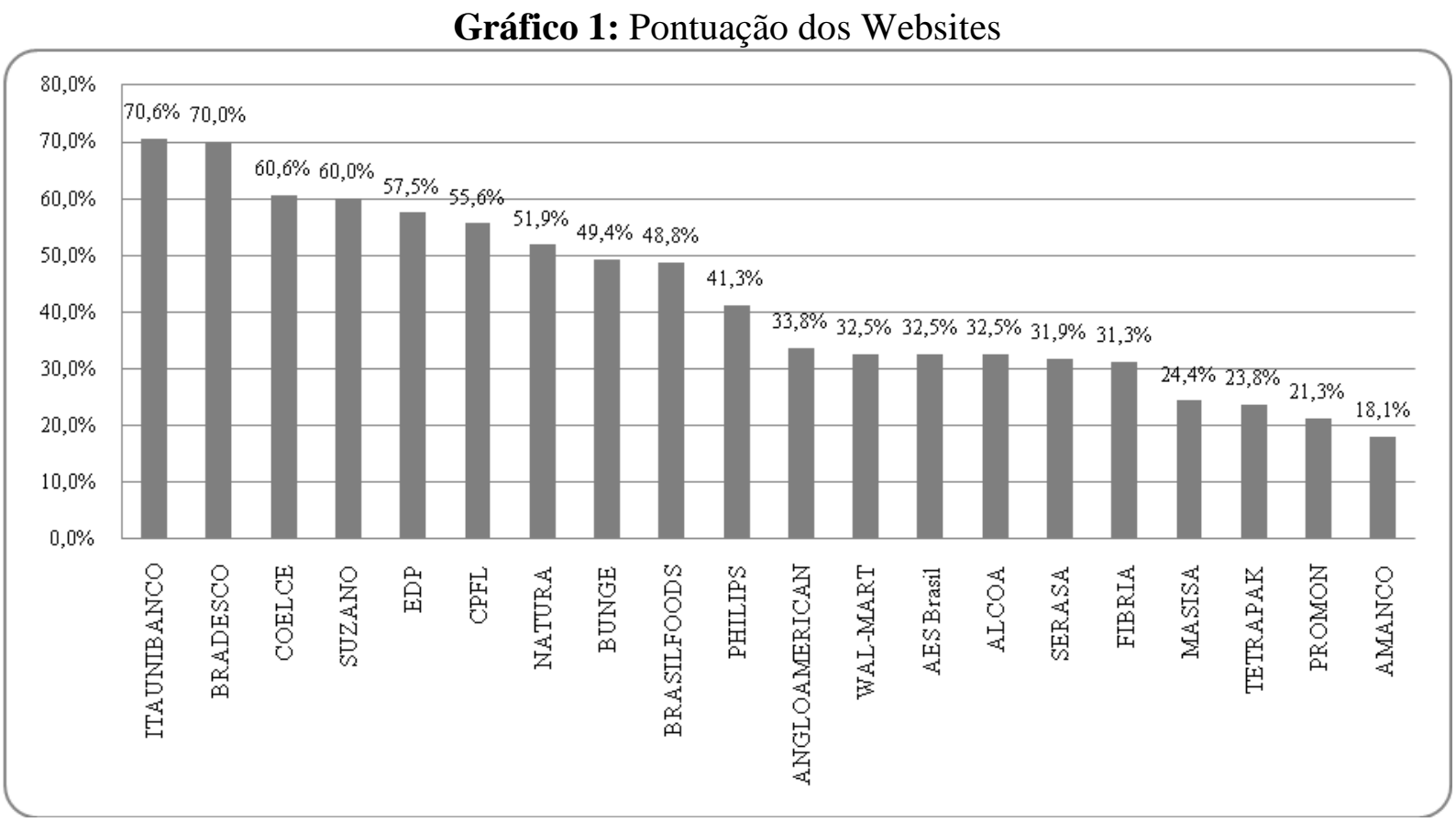

Fonte: Dados da pesquisa.

A expectativa inicial de encontrar uma ampla variedade de informações a respeito das estratégias de responsabilidade social destas empresas não foi concretizada na pesquisa. De acordo com os resultados obtidos, o website com maior pontuação foi do Itaunibanco que apresentou uma pontuação de 565 (70,6\% pontos percentuais dos itens possíveis), seguido do Grupo Bradesco, que obteve 560 pontos $(70,0 \%)$.

Portanto, de acordo com os critérios utilizados neste trabalho para avaliar os websites das empresas no Brasil, estes dados apontam há muito trabalho a ser feito pelas organizações para aumentarem seu grau de comunicação e interação com os públicos de interesse assim como em relação a comunidade mais ampla. Longe de querermos esgotar todas as possibilidades do tema, trata-se aqui apenas de apresentar uma proposta inicial de avaliação de websites corporativos e reter alguns dados a serem retomados e desenvolvidos posteriormente através de estudos de caso com maior profundidade.

\section{CONSIDERAÇÕES FINAIS}

O objetivo do presente trabalho foi apresentar uma proposta de estudo voltada para mensuração do grau de utilização da Internet pelas empresas brasileiras, visando avaliar como estas organizações se utilizam da web para divulgar suas ações de RSC e interagir com seus stakeholders. Para isso, foram analisados os websites das 20 maiores empresas líderes em responsabilidade social corporativa no Brasil, segundo classificação do Guia Exame de Sustentabilidade (2009). 
O que se pode perceber na análise dos resultados é que há bastante heterogeneidade no desenho dos websites corporativos, tanto no que se refere aos conteúdos, quanto aos formatos de apresentação. Assim, podemos observar a existência de portais que equilibram de maneira razoável as várias dimensões da responsabilidade social, divulgando informações claras e suficientes sobre o desempenho social, econômico e ambiental da empresa, até sites que possuem pouca informação a respeito.

Para a maioria das empresas, os tópicos relacionados à responsabilidade social são de grande importância. Isso pode ser observado pelo fato de que um grande número de websites possui uma seção exclusiva dedicada à responsabilidade social/ sustentabilidade na página inicial $(75 \%)$ do site da companhia. A presença desta informação implica um reconhecimento desta questão que serve como um indicador do reconhecimento e da importância da comunicação da responsabilidade social corporativa para as empresas em seus websites corporativos.

Entretanto, esta pesquisa também observou que as empresas ainda não estão explorando muitas das possibilidades da mídia Internet para divulgar suas estratégias de responsabilidade social, assim como para se comunicar e interagir com os públicos interessados. Esta conclusão é reforçada, principalmente, ao levar-se em consideração o baixo índice de utilização de recursos interativos (como medidas de opinião, enquetes, chat, fórum, blogs, discussão sobre temas específicos ligados à responsabilidade social/ sustentabilidade, etc.), que são disponibilizados de maneira pouco freqüente pelas empresas em seus websites. Os resultados claramente mostram que os mecanismos de comunicação e interação ("com") foram pouco utilizados, o que demonstra que apesar das enormes vantagens contidas nestas novas tecnologias, a comunicação da responsabilidade social na internet ainda se caracteriza por uma via de mão única, focada apresentação de conteúdos eminentemente de caráter informativo, sem a preocupação com uma participação mais efetiva dos públicos interessados nos negócios da empresa.

Deve-se sublinhar, por fim, que a presente pesquisa se constituiu numa primeira aproximação ao tema. Acreditamos que estudos futuros que pudessem conciliar, por um lado, uma quantidade de websites de companhias significativas por segmento e regiões e, por outro, mecanismos mais sofisticados de avaliação do conteúdo dos websites para as empresas divulgarem sua marca e os programas de RSC poderiam levam a pesquisa sobre o tema para novos patamares, provocando efeitos multiplicadores na própria gestão dos websites ou dos portais empresariais. Tal agenda de pesquisa e de ações práticas viria a se constituir em importante avanço neste campo de estudos, além de oferecer um panorama mais completo sobre o uso destas novas tecnologias pelas empresas e a responsabilidade social no Brasil.

\section{REFERÊNCIAS}

Ashley, P. A. (2005). Responsabilidade social empresarial: um modelo genérico para análise e orientação estratégica. In P. A. Ashley (Coord). Ética e Responsabilidade Social nos negócios (2a ed, Cap. 6, pp. 110-155). São Paulo: Saraiva.

Ashley, P. A. \& Cardoso, J. G. (2002). A responsabilidade social nos negócios: um conceito em construção. In P. A. Ashley (Coord). Ética e Responsabilidade Social nos negócios (1a ed, Cap. 1, pp. 2-16). São Paulo: Saraiva.

Ashley, P. A., Ferreira, R. N. \& Reis, H. L. (2006). Corporate Strategies for Business Comparative Model Applied in Three Continents. Anais da Rio Oil \& Gas Expo and Conference, Rio de Janeiro, RJ, Brasil. 
Birth, G. B., Illia, L., Lurati, F. \& Zamparini, A. (2008). Communicating CSR: practices among Switzerland's top 300 companies. Corporate Communications, 13 (2), 182-196.

Braga, S. S. \& Nicolas, M. A. (2009). Os empresários, a política e a Web: mapeando as atividades políticas nos portais das Federações das Indústrias brasileiras. Sociedade e Estado, Brasília, 24(2), 439-490.

Capriotti, P. \& Moreno, A. (2007). Corporate citizenship and public relations: The importance and interactivity of social responsibility issues on corporate websites. Public Relations Review, 33(1), 84-91.

Carroll, A. B. (1979). A three-dimensional conceptual model of corporate performance. Academy of Management Review, 4(4), 497-505.

Davis, K. (1973). The case for and against business assumptions of social responsibilities. Academy of Management Journal, 16(1), 312-322.

Downes, E. J. \& Mcmillan, S. J. (2000). Defining interactivity: A qualitative identification of key dimensions. New Media \& Society, 2(2), 157-179.

Editora Abril (2009). Guia Exame de Sustentabilidade: a lista das 20 empresas-modelo em responsabilidade social corporativa no Brasil. São Paulo, SP: Autor.

Esrock, S. L. \& Leichty, G. B. (1998). Social responsibility and corporate web pages: Selfpresentation or agenda-setting? Public Relations Review, 24(3), 305-319.

Esrock, S. L. \& Leichty, G. B. (2000). Organization of corporate web pages: publics and functions. Public Relations Review, 26(3), 327-344.

Fiório, S. L., Nossa, S. N., Costa, R. A, Pereira, A. N. \& Nossa, V. (2008). A Responsabilidade Social Corporativa nos Informes Empresariais do Setor de Telecomunicações: uma análise exploratória e documental. Contabilidade, Gestão e Governança, 11(1-2), 279-295.

Frederick, W.C. (1978). From CSR1 - CSR2. The maturing of the business and society thought, Business \& Society, 33(1), 150-64.

Freeman, R. E. (1984) Strategic management: a stakeholder approach. Boston: Pitman.

Friedman, M. (1970, September 13). The social responsibility of business is to increase its profits. New York Times Magazine, 33, pp.122-126.

Gill, D. L., Dickinson, S. J. (2008). Communicating sustainability: A web content analysis of North American, Asian and European firms. Journal of Communication Management, 12(3), 243-262.

Ha, L. \& James, E. L. (1998). Interactivity reexaminated: A baseline analysis of early business websites. Journal of Broadcasting \& Electronic Media, 42(4), 457-474.

Hill, L. N. \& White, C. (2000) Public relations practitioners' perception of the world wide web as a communications tool. Public Relations Review, 26(1), 31-51.

Kent, M. L. \& Taylor, M. (1998). Building dialogic relationships through the world wide web. Public Relations Review, 24(3), 321-334. 
Kent, M. L., Taylor, M. \& White, W. J. (2003). The relationship between web site design and organization responsiveness to stakeholders. Public Relations Review, 29(1), 63-77.

Morsing, M. (2006). Corporate Social Responsibility as strategic auto-communication: on the role of external stakeholders for member identification. Business Ethics, 15(2), 171-182.

Santiago, R. D. \& Gomes, E. G. (2008). Estratégias de Responsabilidade Socioambiental: análise comparativa dos conteúdos dos websites de entidades fechadas de previdência complementar. Anais do Congresso Nacional de Excelência em Gestão, Rio de Janeiro, RJ, Brasil, 4.

Pollach, I. (2003). Communicating corporate ethics on the world wide web: a discourse analysis of selected company web sites. Business and Society, 42(2), 277-87.

Schwartz, M. S. \& Carroll, A. B. (2003). Social Responsibility: a three-domain approach. Business Ethics Quarterly, 13(4), 503-530.

Schwartz, M. S. \& Carroll, A. B. (2008). Integrating and Unifying Competing and Complementary Frameworks: The Search for a Common Core in the Business and Society Field. Business and Society, 47(2), 148-186.

Silva, F. F., Wanderley, L. S., Perks, K. J. \& Souza, J. M. (2007). Responsabilidade Social das Empresas na web: estratégias de divulgação adotadas por empresas no Brasil e na França. Anais do Congresso do Instituto Franco-Brasileiro de Administração de Empresas, Porto Alegre, RS, Brasil, 4.

Sullivan, J. (1999). What are the functions of corporate home pages? Journal of World Business, 34(2), 193-210.

White, C. \& Raman, N. (1999). The World Wide Web as a public relations medium: The use of research, planning and evaluation in web site development. Public Relations Review, 25(4), 405419.

Wood, D. J. (1991). Corporate Social Performance Revisited. The Academy of Management Review, 16(4), 691-718.

Data do recebimento do artigo: 21/10/2011

Data do aceite de publicação: 16/12/2011

Revista de Gestão Social e Ambiental - RGSA, São Paulo, v. 5, n. 3, p. 150-167, set./dez. 2011. 